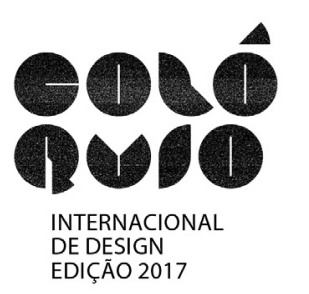

\title{
Utilização da metodologia Design Thinking e estratégias de gamificação para reinventar a experiência com EAD.
}

\author{
Laura Tuma De Athayde; \\ Marina Rabelo Moreira; \\ Juliana Hollerbach De Aguilar
}

\begin{abstract}
resumo:
Como reinventar a experiência de uma aula no modelo de Ensino a Distancia (EaD)? Através da utilização da metodologia design thinking foi criado um modelo para gerar alternativas para melhorar a experiência a partir de um estudo de caso de EaD recém implantado em uma instituição de ensino. Dentro deste contexto foi diagnosticado os elementos para tornar uma aula EaD mais agradável focando na aprendizagem utilizando o design de interface como meio de interação para apresentar as propostas. A pesquisa bibliográfica aborda os fundamentos, evolução e ferramentas principais da Educação à Distância, o Design Instrucional e a Gamificação. A opção pela gamificação deu-se pela alta recomendabilidade da aplicação dessa moderna estratégia em sistemas de $\mathrm{EaD}$, dado que propõe deixar a experiência do aluno mais prazerosa e eficiente, mantendo a qualidade da aprendizagem com a proposta de evitar a desistência. Os procedimentos adotados dentro da metodologia Design Thinking abrangem desenvolvimento de personas, pesquisa de imersão, mapa mental e análise de protótipos e compõem um modelo para aplicar a metodologia ao desenvolvimento de interface a projetos de EaD. Esta pesquisa classifica-se como aplicada quanto sua natureza, qualitativa quanto a sua forma de abordagem, exploratório-descritiva em relação a seus objetivos, e do ponto de vista dos procedimentos técnicos enquadra-se como estudo de caso e reafirma o design quanto atividade multidisciplinar que introduz novos significados para a experiência humana.
\end{abstract}

palavras-chave:

Design Instrucional; Design Thinking; Gamificação; Design de Interface; Experiência. 


\section{Introdução}

A evolução da Educação a Distância - ou EaD - está diretamente relacionada ao desenvolvimento dos meios de comunicação - correspondências, rádio, televisão, e internet (MAIA; MATTAR, 2007). Estes novos métodos foram possibilitando acessos cada vez mais rápidos à comunicação, permitindo um maior nível de interatividade (PINHEIRO, 2002 apud PREVEDELLO, 2011). Neste contexto, passam a ser valorizados os processos de buscar, encontrar, selecionar e aplicar uma informação, diferente do antigo processo de receber e memorizar (MAIA; MATTAR, 2007; PREVEDELLO, 2011)

A interface da $\mathrm{EaD}$ é de extrema importância, pois ela é a responsável pela aproximação do aluno com o conteúdo, e deve ser bem feita para efetivar o aprendizado (PREVEDELLO, 2011). Diante disso, reinventar a experiência com o EaD consiste em elaborar uma proposta de layout considerando o desenvolvimento de uma interface que proponha diversos tipos de interação, de modo a proporcionar a aprendizagem. Trata-se, portanto, de uma experiência em design de interação, em que se busca criar experiências que melhorem a forma como as pessoas trabalham, se comunicam ou interagem (PREECE; ROGERS; SHARP, 2005 apud MENDES, 2009).

Norteado pelo design instrucional, cujo objetivo é desenvolver experiências que efetivamente possibilitem a aprendizagem, este artigo diagnostica, através da teoria e da aplicação da metodologia de Design Thinking, a gamificação como um caminho a ser seguido para promover tanto a interação quanto proporcionar uma experiência positiva que assegure este ambiente de aprendizagem.

Com o objetivo de reinventar a experiência de um modelo em fase de testes e recém implantado de EaD de uma instituição de ensino - a Faculdade INAP, de Belo Horizonte (MG) que visa a expansão de suas atividades para além dos muros físicos da instituição, podendo, idealmente, abranger todo o território nacional. O projeto foi desenvolvido tendo como base as experiências, necessidades e expectativas dos alunos e professores. A presente pesquisa classifica-se como aplicada quanto sua natureza, qualitativa quanto a sua forma de abordagem, exploratório-descritiva em relação a seus objetivos, e do ponto de vista dos procedimentos técnicos enquadra-se como estudo de caso.

A proposta de aplicar o Design Thinking como metodologia para reinventar a experiência em $\mathrm{EaD}$ foi elaborada mediante duas etapas: a primeira consistiu na revisão bibliográfica para obter a fundamentação teórica dos principais conceitos pertinentes ao tema; a segunda ocorreu através do desenvolvimento do projeto teórico-prático para criação de interface centrada no usuário visando solucionar o problema de pesquisa.

Os procedimentos adotados dentro da metodologia Design Thinking abrangeram desenvolvimento de personas, pesquisa de imersão, mapa mental e análise de protótipos e formam um modelo para aplicação em desenvolvimento de interface para cursos de EaD.

\section{Base teórica}

\subsection{A Educação a Distância e suas especificidades}

A comunicação conseguiu se libertar do tempo e do espaço no momento que foi inventada a escrita. Quando se escreve em um suporte, deixa de ser necessário que as pessoas estejam presentes no mesmo momento e local (MAIA; MATTAR, 2007).

O decreto $n^{0}$ 5.622, de 19 de Dezembro de 2005 - a Lei de Diretrizes e Bases da Educação Nacional - caracteriza a EaD como sendo uma modalidade na qual a mediação didático-pedagógica nos processos de ensino e aprendizagem ocorre com a utilização de meios e tecnologias de informação e comunicação, com estudantes e professores desenvolvendo atividades educativas em lugares ou tempos diversos (BRASIL, 2005).

Portanto, a EaD é uma modalidade de ensino em que os professores e os alunos estão separados fisicamente. Essa proposta de educação é fundamentada na filosofia de que o aprendizado deve ocorrer também fora da sala de aula. Por isso, como os participantes não estão presentes no mesmo local, é fundamental o uso das tecnologias de comunicação (MAIA; MATTAR, 2007). 
Outra diferença importante do Ensino a Distância para o ensino tradicional é que muitas das atividades são assíncronas, isto é, não ocorrem ao mesmo tempo. Isso possibilita que o aluno e o professor acessem as atividades e se comuniquem em instantes diferentes. Essa separação no tempo permite que o estudante controle sua rotina e se programe para estudar de acordo com a sua necessidade e sua disponibilidade (MAIA; MATTAR, 2007).

Segundo o relatório da comissão assessora de Educação a Distância do Brasil, para o desenvolvimento de curso $\mathrm{EaD}$, deve-se considerar, além de um processo de ensino e aprendizagem com organização curricular, interação entre alunos e professores, formas de avaliação do ensino e da aprendizagem dentre outros (MAIA; MATTAR, 2007).

Daniel e Mackintosh (2003) acreditam que, para que o ensino a distância seja ofertado de forma eficiente, devem ser utilizados materiais de estudo que explorem a multimídia e sejam de excelente qualidade, para promover um aprendizado independente e autônomo.

Belisário (2011) salienta a importância de metodologias mais afinadas com o progresso tecnológico, que permitam a interatividade do aluno com o sistema. A interatividade, nesse contexto, tem três fundamentos: participação ou interação, entendida como a possibilidade de realização de modificações na mensagem pelo aluno; bidirecionalidade ou hibridação, significando a emissão e recepção simultâneas da mensagem; e, finalmente, permutabilidade ou potencialidade, caracterizada pela liberdade de trocas, associações e significações entre os envolvidos no processo de aprendizado (professores e alunos).

$\mathrm{O}$ design de interação busca criar experiências que melhorem a forma como as pessoas trabalham, se comunicam ou interagem (PREECE; ROGERS;SHARP, 2005 apud MENDES, 2009). As principais atividades que envolvem o processo de Design de Interação são: (PREECE; ROGERS;SHARP, 2005 apud MENDES, 2009).

- identificar necessidades e estabelecer requisitos;

- desenvolver designs alternativos que preencham esses requisitos;

- construir versões interativas dos design de maneira que possam ser comunicados e analisados;

- avaliar o que está sendo construído durante todo o processo

Neste contexto, a interface da EaD é de extrema importância, pois ela é a responsável pela aproximação do aluno com o conteúdo, e deve ser bem feita para efetivar o aprendizado (PREVEDELLO, 2011) e promover interações.

O papel do design instrucional nessa modalidade é de organizar o conteúdo e desenvolver experiências que efetivamente possibilitem a aprendizagem. Filatro (2004) define o design instrucional como uma ação de ensino que tem por objetivo facilitar a aprendizagem. Ele envolve o processo de identificar problemas, necessidades, de aprendizagem e de desenvolver, avaliar e implementar soluções. Para isso são utilizados atividades, materiais, técnicas e produtos educacionais (FILATRO,2004 apud PREVEDELLO, 2011).

Seu intuito é resolver a forma como o conteúdo deverá ser percorrido pelo aluno, quais serão as formas de interação e as tecnologias utilizadas (MAIA; MATTAR, 2007). Para realizar este desenvolvimento, devem ser considerados as características dos usuários, como sua localização geográfica, as tecnologias às quais têm acesso, seus objetivos enquanto estudantes, os custos e o posicionamento da instituição no mercado (MAIA; MATTAR, 2007). Neste contexto, a metodologia de design thinkig se aplica.

\subsection{Design Thinking e sua aplicabilidade ao desenvolvimento de uma interface de EaD}

Segundo Martin (2009) o Design Thinking é uma forma diferente de o designer pensar, de encontrar soluções, de suprir necessidades, de otimizar experiências e de satisfazer o consumidor. É um processo, um método de inovação que é focado nos aspectos humanos. O conceito de Design Thinking foi introduzido em 1974 por Papaneck, Fuller e Caplan, com a tentativa de tornar a abordagem do design mais estratégica, indo além do estético e aingindo a funcionalidade. Seria um meio de imaginar situações futuras e desenvolver produtos, serviços e experiências para o mercado (BALEM, 2011). Buscando soluções inovadoras para os negócios, o Design Thinking propõe uma abordagem focada no ser humano que vê na multidisciplinaridade, colaboração e tangibilização de pensamentos e processos (SILVA et al. 2012). 
As experiências são acontecimentos individuais que ocorrem como resposta a algum estímulo. São o resultado de uma observação direta e /ou de participação nos acontecimentos reais, imaginários ou virtuais. (SCHMITT, 2002). Como o Design Thinking aborda os problemas com o foco no usuário, as soluções obtidas tendem a ser mais adaptadas às suas necessidades. Por isso possuem maiores índices de adoção e aceitação (PINHEIRO, 2010 apud BALEM, 2011).

\subsection{Gamificação como estratégia de aprimoramento do EAD}

Gamificação, ou gamification, consiste em usar técnicas, estratégias e o design de games em outros contextos que não sejam apenas de jogos. É trazer o jogo para a realidade e, com isso, impactar pontos como engajamento, produtividade, foco, determinação e outros, tornando mais simples atingir metas e objetivos em qualquer contexto (TAMEIRÃO, 2016).

Alguns dos critérios empregados em jogos e que podem auxiliar na conquista de objetivos e aumento da produtividade em outras atividades são o entretenimento, a competição, a instantaneidade da comunicação (especialmente de comentários e pareceres), a sensação de evolução e a oferta de recompensas.

Tameirão (2016) destaca algumas vantagens em investir na gamificação de sistemas de educação à distância. São elas: maior engajamento e motivação dos alunos, o que pode ser atingido através de um sistema de desafios e recompensas; a facilitação do aprendizado e, consequentemente, a evolução mais rápida mediante comentários instantâneos sobre a sua produtividade; e o direcionamento a um objetivo, facilitado por um sistema de fases e pontos que deixe o aluno ciente do seu nível e do quanto ainda precisa desenvolver-se para finalizar cada etapa (TAMEIRÃO, 2016).

A autora reforça esses pontos afirmando que a gamificação de um sistema de $\mathrm{EaD}$ deve ocorrer através da criação de um sistema de pontuação e evolução, a oferta de prêmios, o estímulo à competição saudável entre os alunos e a oferta de comentários rápidos e constantes sobre a evolução destes (TAMEIRÃO, 2016).

Outro ponto de destaque é a criação de uma narrativa, ou storytelling. Isso traz o benefício de tornar o aprendizado do aluno mais envolvente e divertido, inserindo-o dentro de um contexto narrativo específico e oferecendo estímulo extra para a consecução dos seus objetivos - no caso, o progresso na história ou no universo em que está inserido o conteúdo do ensino à distância.

A criação de um avatar pertencente ao contexto é um elemento a mais que pode conferir diversão ao trajeto do aluno pelas etapas do curso. A oferta de itens especiais e prêmios relacionados ao contexto narrativo serve como um estímulo extra para o engajamento dos alunos e para a fixação dos conteúdos.

Portanto, tornar a experiência de aprendizado mais divertida e estimulante através de estratégias lúdicas empregadas em jogos - tanto no design como na mecânica - não é apenas possível, mas recomendável.

\section{Metodologia}

\subsection{Design Thinking}

O método do Design Thinking pode ser resumido basicamente em quatro etapas: imersão, ideação, prototipação e implementação. Na imersão busca-se um aprofundamento no contexto do problema, buscando os pontos de vista do cliente, do usuário final e do ambiente. Na ideação, começa-se a estimular a criatividade para gerar ideia inovadoras e soluções adequadas ao contexto. Na prototipação passa-se a ideia do abstrato para o físico, mesmo que simplificadamente, para que estas possam ser avaliadas. A implementação é quando se aplica realmente a solução encontrada, sendo importante continuar analisando seus efeitos. Estas etapas não são lineares e podem ser realizadas e repetidas sempre que necessário (SILVA, 2012). 


\section{Desenvolvimento e resultados}

Como mencionado no item 1 deste artigo, o projeto foi desenvolvido tendo como base as necessidades dos alunos da Faculdade INAP, instituição de ensino belo-horizontina que completa, em 2017, 41 anos de funcioamento. A referida escola oferece cursos técnicos, de graduação e de pós-graduação nas áreas de Design e de Arquitetura. Atualmente, a instituição decidiu ofertar matérias à distância, para flexibilizar a carga horária, dar maior autonomia aos alunos e incentivar a pesquisa. Futuramente, poderão ser disponibilizados cursos técnicos integralmente online (INAP, 2017).

A demanda apresentada, portanto, foi a necessidade de um layout de interface para a implementação de um sistema eficiente de $\mathrm{EaD}$ condizente com a expectativa dos alunos. A proposta de layout foi elaborada conforme a metodologia de Design Thinking, como descrito no item anterior. Neste contexto foi criado um modelo para desenvolvimento de interface para $\mathrm{EaD}$ aplicando a metodologia Design Thinking.

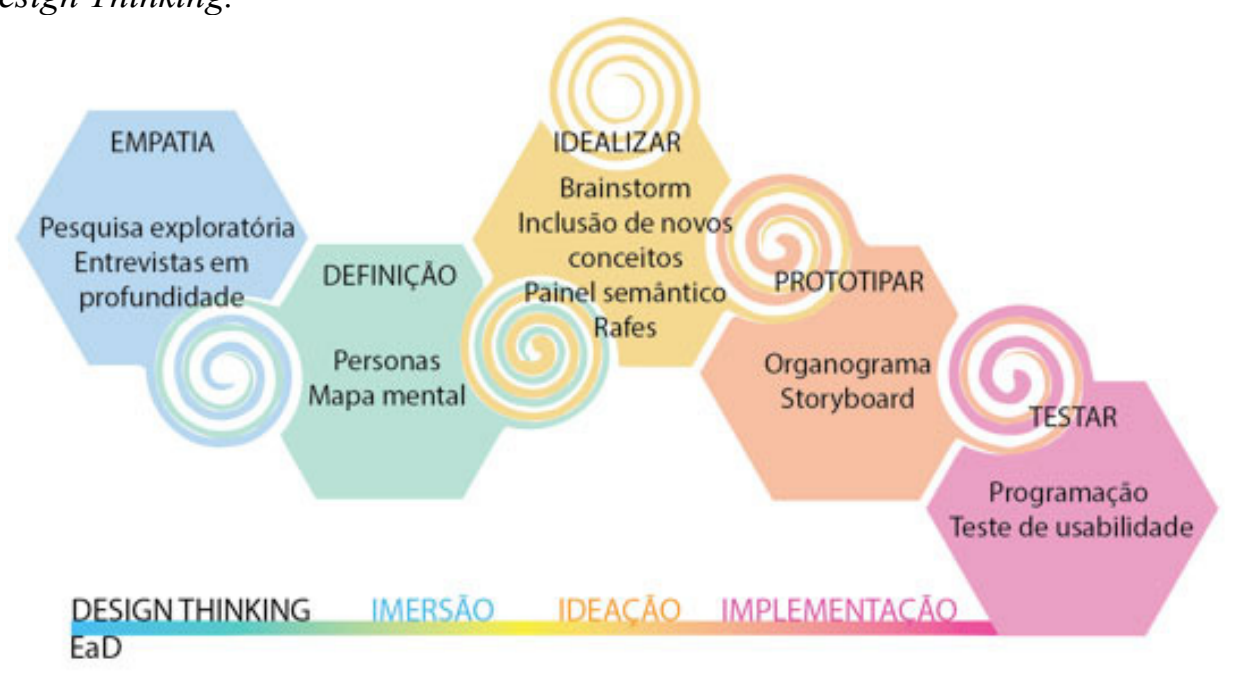

Quadro 1: Modelo proposto

Fonte: Desenvolvido pelas autoras, 2017

\subsection{Etapa 1: Imersão}

No desenvolvimento da pesquisa descrita neste artigo, a etapa de imersão compreendeu a pesquisa sobre o cliente - sua história, características e necessidades - e a a entrevista com potenciais usuários do sistema de $\mathrm{EaD}$ - no caso, alunos da instituição de ensino Faculdade INAP - acerca de suas expectativas, experiências e necessidades relativamente à modalidade de Ensino a Distância. Em seguida, foram elaborados mapas mentais e um conjunto de personas com base nas informações obtidas.

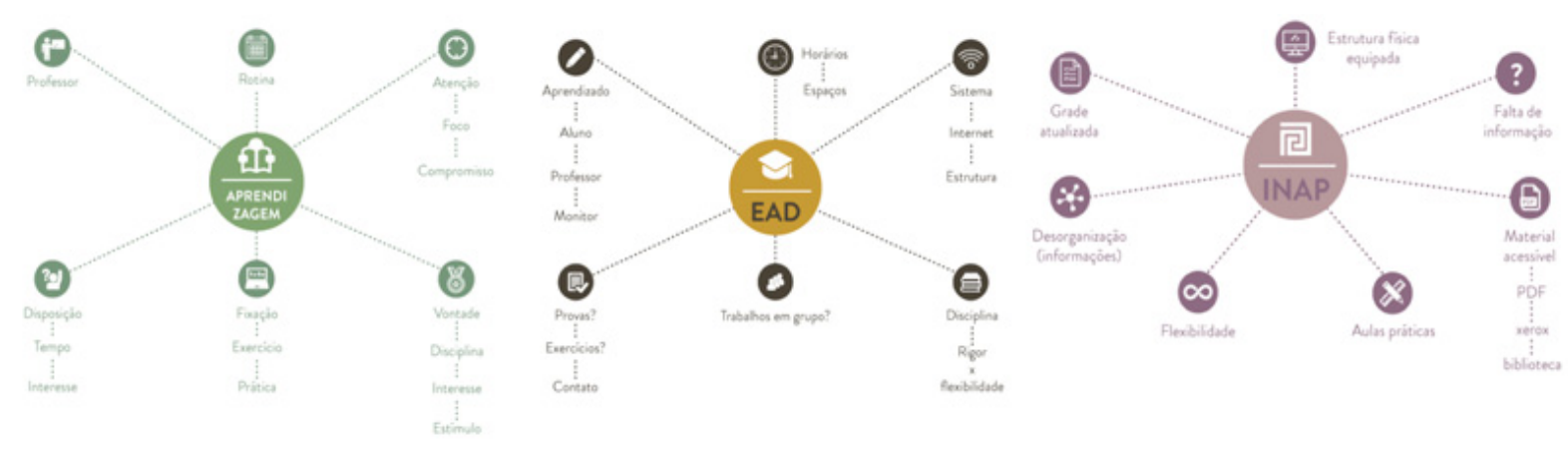

Quadro 2: Mapas mentais

Fonte: Desenvolvido pelas autoras, 2017 


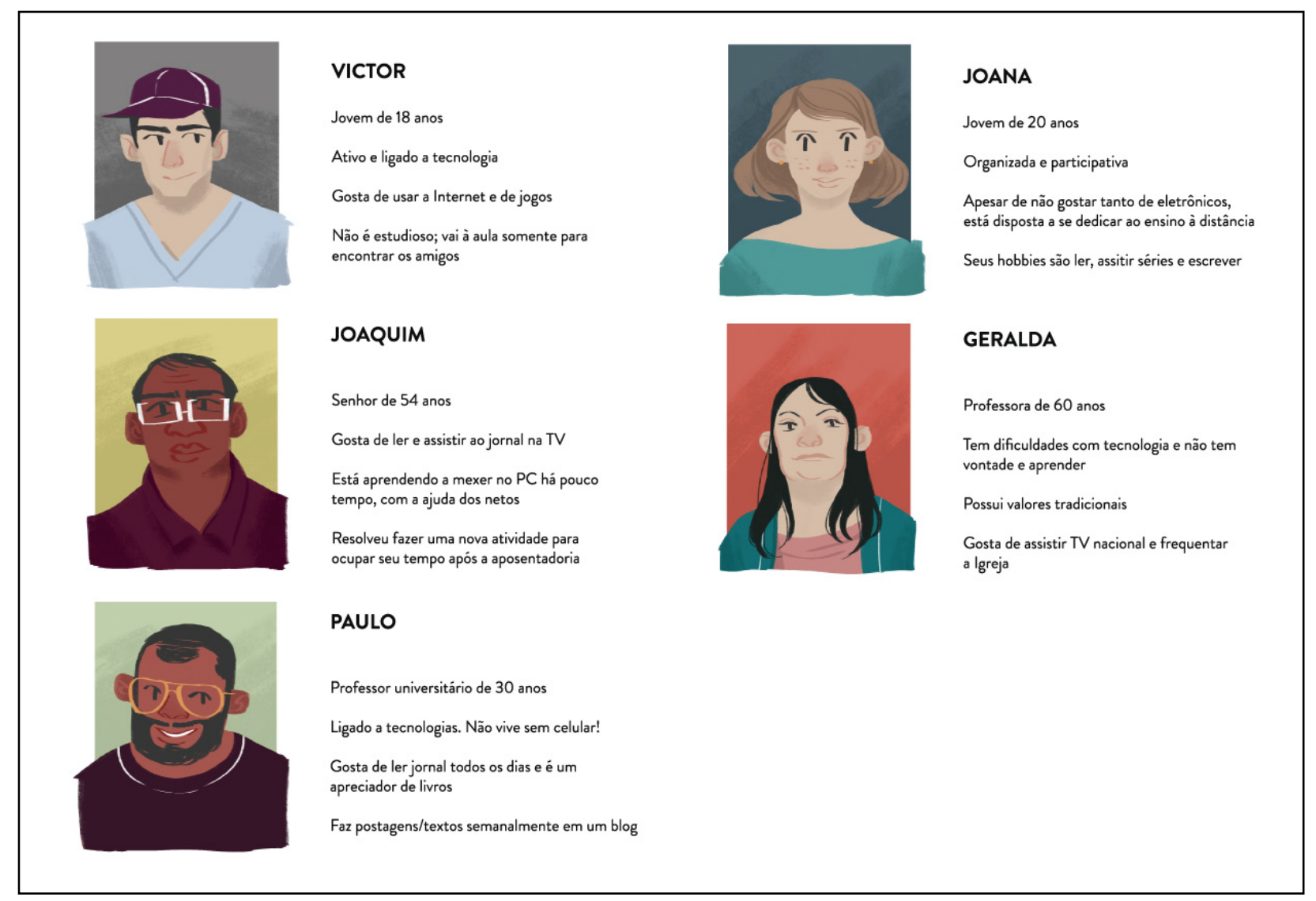

Quadro 3: Personas

Fonte: Desenvolvido pelas autoras, 2017

\subsection{Etapa 2: Ideação}

$\mathrm{Na}$ etapa de ideação, foram feitas reuniões e brainstorm entre as autoras e alguns alunos da instituição de ensino em questão, discutindo as funcionalidades essenciais do sistema de $\mathrm{EaD}$ e formas de deixálo mais dinâmico.

Decidiu-se que as telas de aulas deveriam ter suporte para vídeo, slides com acompanhamento de áudio explicativo, textos para leitura complementar e espaço para que o aluno possa dar o feedback sobre a aula que assistiu, aumentando, assim, a interatividade e simulando, da melhor forma possível, o ambiente de uma sala de aula real.

Como mencionado no item 2.3, um sistema de desafios e recompensas é essencial para a efetiva gamificação de um sistema. Portanto, como forma de obter a pontuação a ser utilizada nesse sistema de recompensas, seriam feitas avaliações presenciais, questionários virtuais após o encerramento de cada unidade a distância e deveria existir a possibilidade de os alunos enviarem para o professor eventuais atividades para correção. A pontuação, por dua vez, deveria ser revertida em prêmios externos ao sistema virtual, contudo relacionados ao contexto acadêmico, como forma de engrandecer a experiência educacional.

Também foi decidido que deveria existir um mapa indicando a carga horária cumprida, a carga horária restante para a conclusão de determinada matéria, a pontuação do aluno e o seu progresso dentro de cada unidade de matérias.

Os alunos e professores deverão ter perfis customizáveis com informações pessoais sobre seus interesses e desempenho acadêmico.

Finalmente, decidiu-se que seria importante incluir um chat periódico entre alunos e professores e uma área de interação de usuários como forma de aumentar a interatividade, conforme a necessidade identificada no item 2.1 . 
Em seguida, foram desenvolvidos rafes de telas do sistema a ser criado, em busca de um layout que contemplasse tanto o aspecto educacional quanto o lúdico, efetivamente aplicando a gamificação à interface.

Para buscar referências em jogos foi criado um questionário utilizando o Google Formulários, para verificar qual as pessoas têm mais familiaridade. Perguntou-se qual a pessoa está jogando no celular no momento, e se ela conhece algum outro. Foi feita uma restrição aos jogos de celular, pois estes são mais acessíveis. A amostra foi de 65 participantes.

Perfil da amostra: as idades variaram de 17 a 59 anos - faixa que é compreendida pelas personas. A maioria possuíam entre 21 e 30 anos. Sendo 40 do sexo feminino e 25 masculino.

De acordo com mas respostas $73,8 \%$ dos participantes jogam no celular e $26,2 \%$ não o fazem até o momento. Analisando as respostas para a pergunta de qual jogo a pessoa já ouviu falar, observase que apenas 2 participantes responderam que não ouviram ou não conseguem lembrar de algum jogo de celular. Então mesmo os que não jogam já viram alguma informação sobre. Isto expressa como eles estão presentes atualmente no cotidiano. Abaixo o quadro comparativo do resumo da pesquisa considerando os jogos que receberam mais de 6 votos no total acrescidos da informação de popularidade no google play e número de avaliações do aplicativo.

\begin{tabular}{|c|c|c|c|c|c|c|}
\hline Jogo & Jogou & $\begin{array}{c}\text { Ouviu } \\
\text { falar }\end{array}$ & $\begin{array}{c}\text { Total de } \\
\text { votos }\end{array}$ & $\begin{array}{c}\text { Downloads no } \\
\text { Google Play }\end{array}$ & $\begin{array}{c}\text { Número de } \\
\text { avaliações do } \\
\text { aplicativo }\end{array}$ & Avaliação \\
\hline $\begin{array}{c}\text { Angry Birds } \\
\text { Candy Crush }\end{array}$ & 0 & 12 & 12 & $\begin{array}{c}\text { Mais de } \\
100.000 .000\end{array}$ & 5.203 .579 & 4,4 \\
\hline Pokemon go & 10 & 20 & 30 & $\begin{array}{r}\text { Mais de } \\
500.000 .000\end{array}$ & 18.287 .007 & 4,4 \\
\hline
\end{tabular}

Quadro 4 - Número de votos dos jogos mais populares entre os participantes e informações disponíveis no Google Play.

Fonte: Desenvolvido pelas autoras, 2017.

O segundo jogo mais votado foi o Angry Birds, que é o terceiro mais baixado. Já o terceiro mais citado foi o Pokemon Go, que apresenta o maior número de downloads. E o quarto com mais votos é o Two Dots, que apresenta menor número de downloads.

Esses jogos foram utilizados como referências para a construção dos elementos de gamificação aplicados ao sistema: um mapa de unidades e o desenvolvimento de um contexto, o storytelling. 
Um dos elementos de gamificação aplicado no desenvolvimento da interface é a construção de um mapa de unidades para cada matéria. Ele é importante para facilitar ao aluno o acompanhamento do seu andamento com os conteúdos da disciplina. Por isso, dos jogos mais citados, quadro 2, foram escolhidos o Candy Crush e o Two Dots como referências, eles possuem as fases dispostas de forma sequencial e linear num mapa, conforme indicado abaixo.
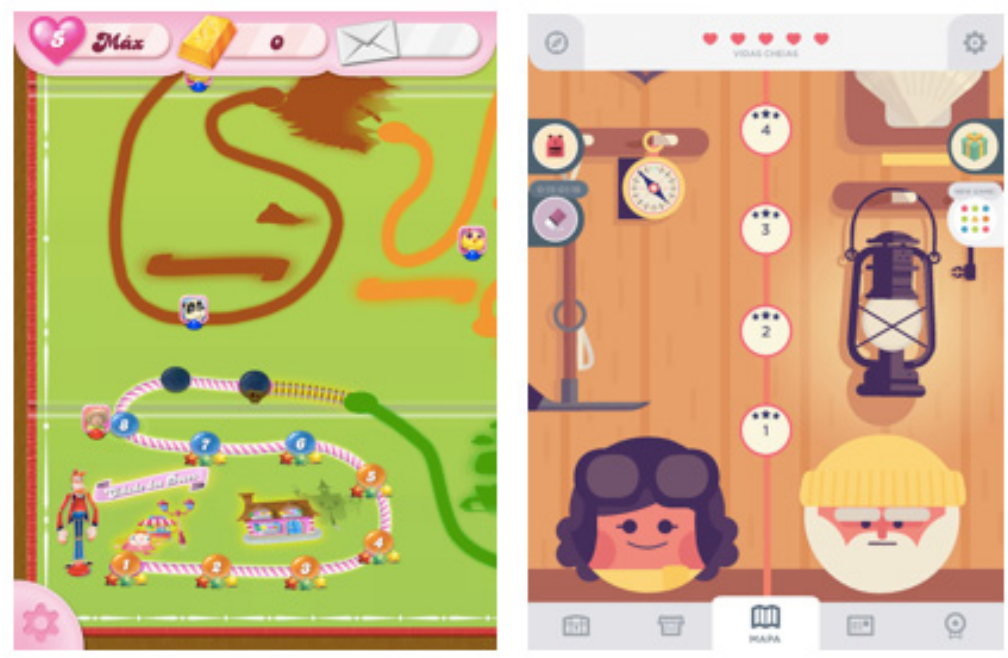

Quadro 5 - À esquerda print tirado da área do mapa do aplicativo Candy Crush. E à direita print tirado da área do mapa do aplicativo Two Dots.

Fonte: PLAYDOTS, 2017 e KING, 2017.

Observa-se que nas duas referências os mapas não apresentam ramificações. As fases são apresentadas sequencialmente, com sua numeração indicada dentro do círculo, que ao ser clicado inicia o jogo. Com cada círculo também estão estrelas, cada uma indica um desafio, como conseguir determinado número de pontos, que foi cumprido ao jogar aquela fase. Considerando as características destes jogos e o mapa estrutural, com a indicação do conteúdo de cada página do sistema, começou-se a desenvolver os rafes dos layouts.

Outra característica de gamification para ser aplicada à interface do sistema é a contextualização. Esse é um detalhe que exige atenção pois deve agradar a todas as personas. Considerando que o INAP é uma faculdade focada no ensino de Design, uma contextualização que tenha relação com essa área pode atrair a atenção dos usuários. Ao buscar figuras relacionadas a esta palavra, é comum encontrar imagens indicadas abaixo.
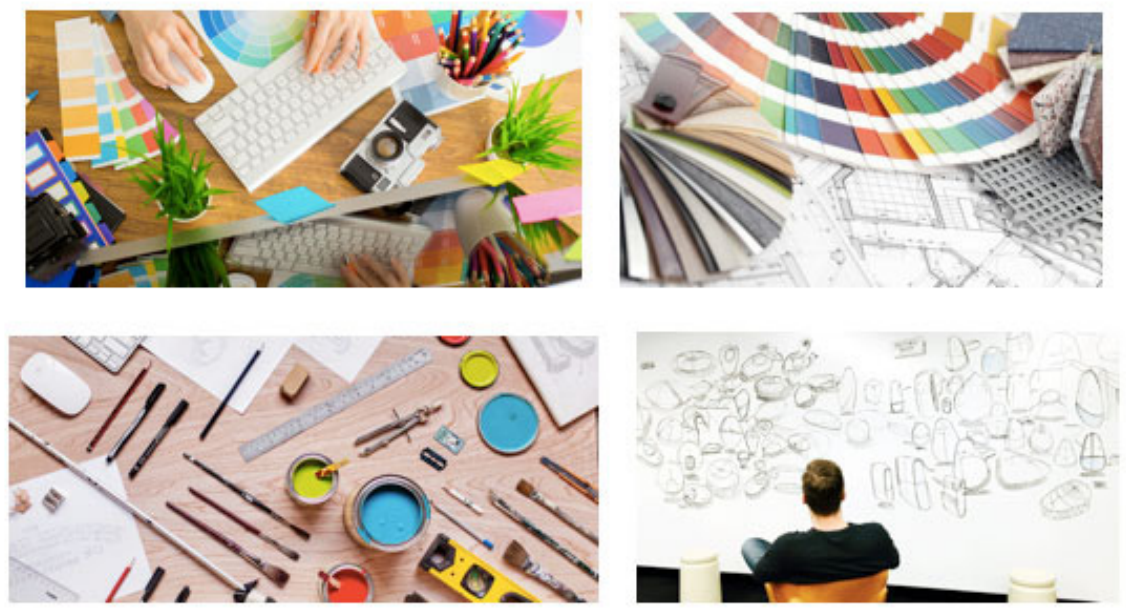

Quadro 6 - Imagens que representam uma mesa de trabalho e materiais de criação Fonte: JOEL, 2017; TURNER, 2014; CF7STUDIO, 2017; IMBODEN, 2016. 
Desta maneira, buscou-se desenvolver os rascunhos dos layouts com a temática do design, tomando cuidado para que as representações não fossem infantis. Na criação dos rafes, optou-se por utilizar um contexto estético e narrativo de mesa de estudos para estruturar o layout das páginas. A escolha se deu pela compatibilidade temática com o contexto educativo do cliente e como forma de simular o ambiente interativo de uma aula presencial, o que, segundo as colocações da pesquisa bibliográfica, é importante em um ambiente de ensino à distância.

Neste contexto, os storyboards foram realizados para desenvolver as funcionalidades e a navegabilidade do sistema. Foram criadas páginas com o layout inspirado na mesa de estudos, com variação dos objetos dispostos sobre ela, assegurando o dinamismo da navegação.

Os objetos decorativos utilizados como suporte para o conteúdo das páginas foram cadernos, jornais, tablets e smartphones. Cada um deles foi utilizado considerando sua aplicação, de forma que um usuário que tem dificuldade de utilizar sistemas eletrônicos, pode navegar relacionando a função ao objeto que já é conhecido no seu dia a dia.

Diante da necessidade explicitada no item 2.3 de elaborar este contexto narrativo para a interface em que os layouts de todas as telas estariam inseridos, optou-se por simular, de forma estilizada, uma mesa de estudos como background. Sobre ela, estariam dispostos objetos de uso cotidiano dos alunos e professores e que se adequassem ao contexto, que, restou decidido, seriam um smartphone, um tablet, um jornal e um caderno. Esses objetos funcionariam como display das informações pertinentes ao sistema, como vídeo-aulas, áudios, chats e outros.

\subsection{Prototipação}

A terceira etapa da medologia de Design Thinking refere-se à prototipação, que consistiu no efetivo desenho das telas como stoyboard e em seguida a elaboração do layout um programa de criação de imagens vetoriais - no caso, o software Adobe Illustrator ${ }^{\circledR}$.

Para a paleta de cores, procurou-se escolher uma série de cores neutras, compatíveis com o contexto educacional e com algumas opções vibrantes para acentuar detalhes importantes. A paleta final tem predominância de tons de azul, marrom e laranja. $\mathrm{O}$ azul foi escolhido por sua associação às virtudes intelectuais; o laranja, por ser claro e vibrante e, portanto, cor ideal para ser empregada em poucos e seletos itens cujo destaque se julgou necessário na interface desenvolvida; e o marrom, por sua vez, foi escolhido por "sua naturalidade, a sua falta de artificialidade" (HELLER, 2013) que o tornam uma cor aconchegante e neutra. Além disso, o marrom remete à madeira, que, como já foi dito, é o material que se procurou evocar no fundo do layout, que é a representação gráfica de uma mesa de trabalho. Pela neutralidade e sensação de conforto e segurança que transmite, também foi utilizado em outros itens decorativos utilizados no layout, como folhas de papel e o fundo de celulares e tablets.

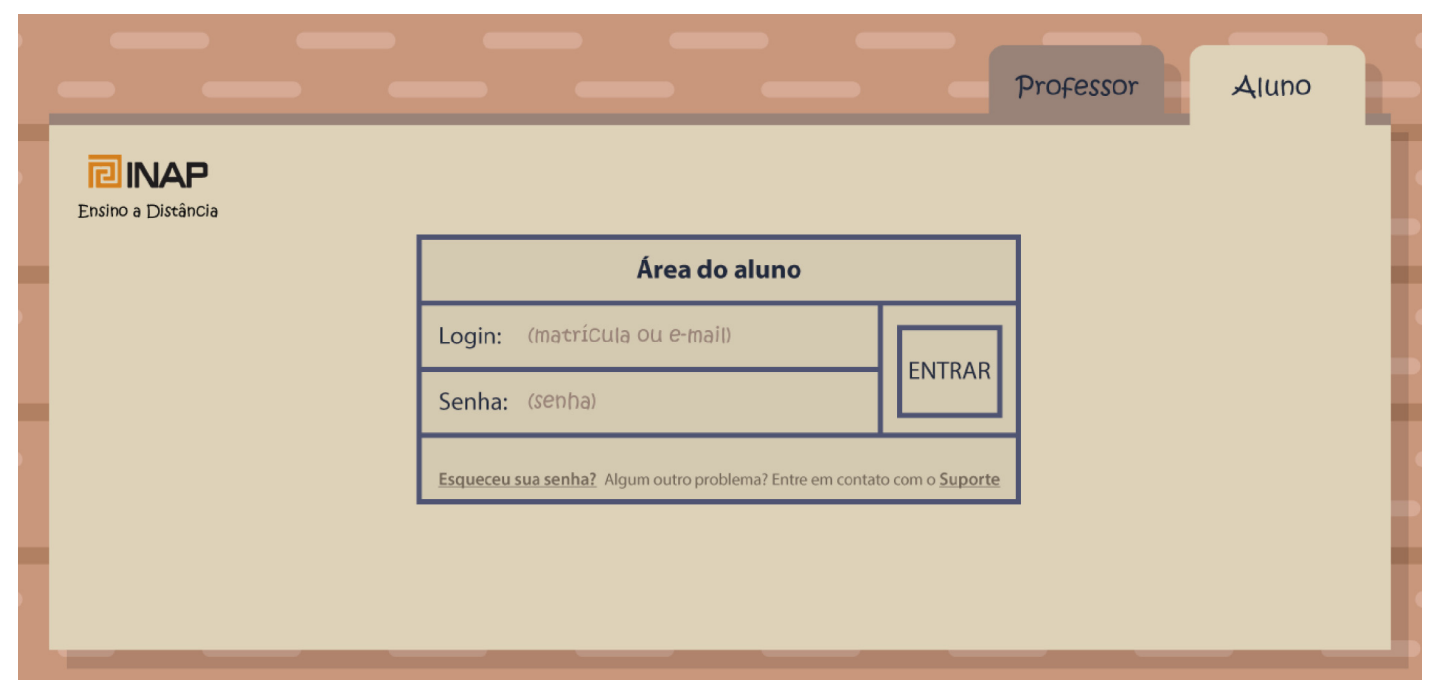

Figura 1: Ambiente de login

Fonte: Elaborado pelas autoras, 2017 

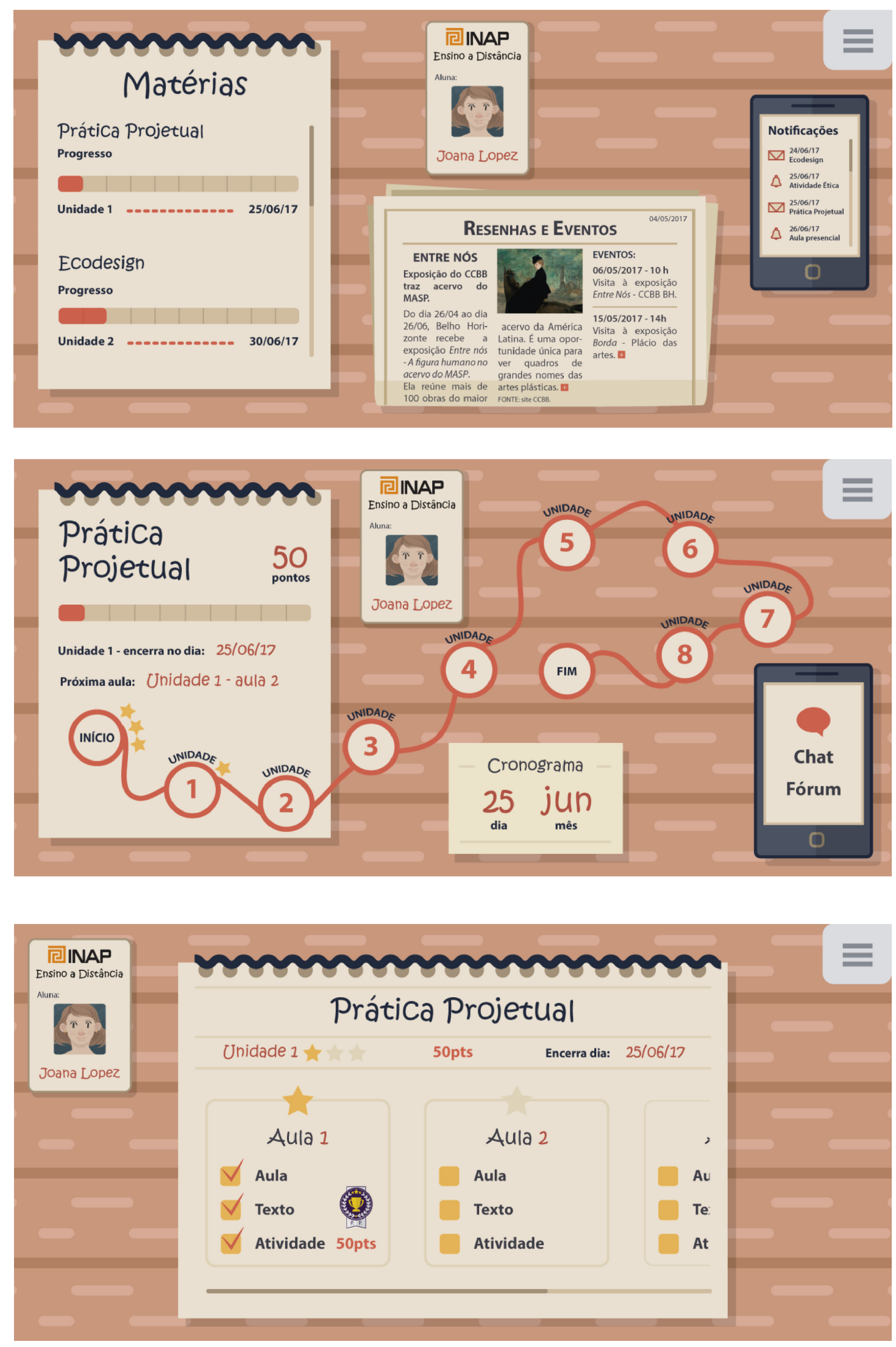

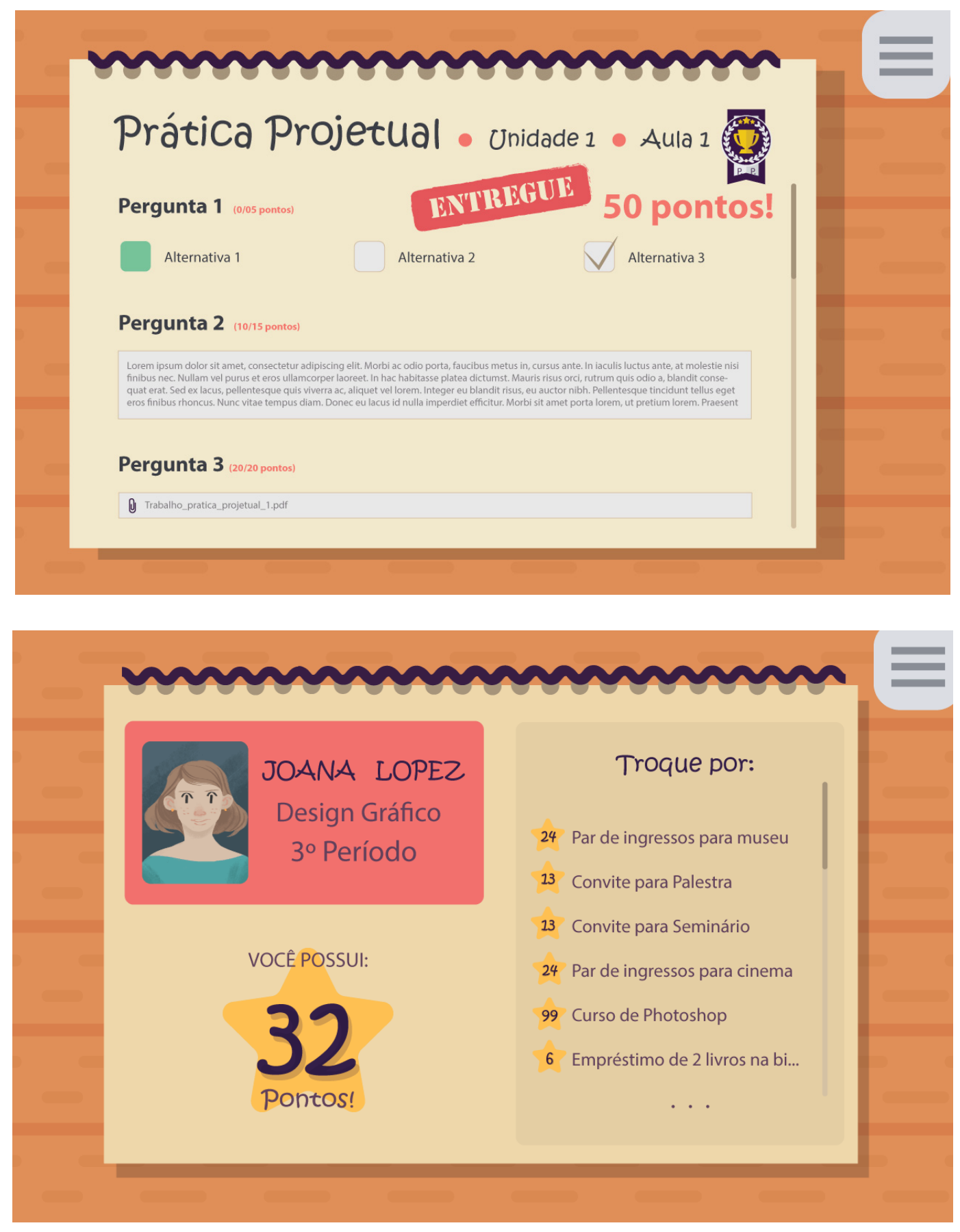

Quadro 7: Layouts desenvolvidos

Fonte: Elaborado pelas autoras

\subsection{Implementação}

Por tratar-se de uma proposta de cunho exclusivamente pedagógico, a etapa de implementação restringiu-se à criação de links entre as telas utilizando o programa de HTML Dreamweaver ${ }^{\circledR}$, de forma a simular a funcionalidade do sistema. Em seguida, foi realizado um teste de usabilidade com 14 alunos e 1 professor dos cursos de graduação de Design Gráfico e Design de Interiores da Faculdade INAP. 
O teste consistiu em observar os usuários reais durante a realização de tarefas numa simulação do sistema (AGNER, 2006). Decidiu-se que as tarefas a serem executadas pelos usuários seriam a sequência mais fundamental do sistema: o acesso à página de aulas, depois à página de atividades e, por último, a de recompensas.

Para isso, o caminho mais curto seria: entrar no sistema através da página de login; clicar no link "Prática Projetual", situado no caderno à esquerda da tela inicial, acessando assim a página específica da matéria; verificar a indicação sobre a próxima aula a ser assistida sob o nome da matéria, no caderno à esquerda da tela, que, no caso, era a segunda aula da unidade 1; clicar no círculo correspondente à unidade no mapa e, em seguida, na aula correta; depois, o usuário deveria ir para a página de atividades, clicar no link "Enviar" e dar "OK" na mensagem pop up que indicava que a atividade estava aguardando correção; após ser direcionado automaticamente para a página de atividade corrigida, deveria clicar no menu sanduíche no canto superior direito da tela e ir para a página de recompensas.

Das pessoas que realizaram o teste, 3 tiveram maior dificuldade, especialmente para identificar o menu e chegar à tela de recompensas. Apesar disso, todos conseguiram chegar à página da matéria começando o acesso pelo caderno de matérias da página inicial, indicando que esse link é importante.

A partir dos testes e da observação da aceitação e dificuldades dos usuários, foram realizadas melhorias no layout, que consistiram em:

- Inserção de link para a página de recompensas na página de atividade corrigida, ao lado da pontuação obtida;

- facilitar a identificação menu, acrescentando a palavra "menu" ao lado do símbolo no canto superior direito da tela;

- colocar o botão de "Enviar" na página de atividade separado das respostas e alterar o texto da barra de envio de atividade de "Enviar" para "Anexar".

\section{Conclusão}

O uso da metodologia do Design Thinking e os conceitos de gamification contribuíram para o desenvolvimento de uma interface que foi bem aceita pelos usuários entrevistados bem como ilustra que o modelo desenvolvido serve de base para aplicação da metodologia e desenvolvimento de interface.

O problema trazido pela Faculdade INAP, no início deste projeto, consistia na necessidade de criação de um sistema de Educação a Distância que permitisse a expansão de suas atividades para além dos muros físicos da instituição, podendo, idealmente, abranger todo o território nacional. Para às suas necessidades, procedeu-se a extensa pesquisa bibliográfica acerca dos fundamentos, evolução e ferramentas principais da Educação à Distância (ou EaD), do Design Instrucional e da Gamificação, ou gamification. A opção pela gamificação deu-se pela alta recomendabilidade da aplicação dessa moderna estratégia em sistemas de $\mathrm{EaD}$, dado que propõe deixar a experiência do aluno mais prazerosa e eficiente, mantendo a qualidade da aprendizagem e evitando a desistência.

$\mathrm{Na}$ fase de imersão, foram realizadas pesquisas sobre o cliente e entrevistas com seus alunos sobre suas experiências e expectativas com sistemas de EaD. A partir dessas entrevistas e dos mapas mentais elaborados pelos entrevistados, foram criadas cinco personas, consistindo em três alunos e dois professores de idades, personalidades e aptidões variadas.

Com base nas referidas personas, passou-se à fase de ideação da interface gráfica, começando pela elaboração de rafes dos layouts de cada tela do sistema com base em referências apuradas em pesquisas realizadas junto ao público usuário de jogos de celular. A opção por pesquisar junto a usuário de jogos deveu-se à decisão de usar a estratégia de gamification no sistema. Além disso, considerando-se as personas e seus variados graus de aptidão tecnológica, concluiu-se que jogos de celular são os mais amplamente acessados por usuários de todas as idades e, portanto, poderiam oferecer opções com as quais indivíduos das mais variadas idades estivessem familiarizadas.

Um ponto de destaque na interface gráfica do sistema desenvolvido é o mapa de fases. O mapa é um recurso comum em jogos para que o jogador possa acompanhar seu desenvolvimento com facilidade; a partir disso, concluiu-se que a criação de um mapa em que estivessem visualmente 
dispostas as "fases" do desenvolvimento do aluno - ou seu progresso nas aulas e, em maior espectro, nas unidades do curso - seria um elemento central no sistema a ser desenvolvido para o cliente. Afinal, o feedback instantâneo e a sensação de evolução constante, assim como a expectativa de conclusão das etapas, são elementos fundamentais na gamificação de sistemas de EaD.

Finalmente, passou-se à fase final do projeto, consistente na prototipação do sistema, ou seja, na elaboração das telas imprescindíveis ao sistema. Neste ponto, optou-se por um contexto narrativo outro requisito do processo de gamificação - que fosse familiar para os alunos de todas as idades e backgrounds e que, ao mesmo tempo, fosse coerente com o ambiente educacional. Diante disso, decidiu-se por ambientar as telas como uma mesa de trabalho, com seus respectivos objetos decorativos, em que as informações essenciais do sistema seriam dispostas: jornal, caderno, smartphone e tablet.

Outro elemento fundamental no sistema desenvolvido, segundo as pesquisas desenvolvidas acerca de gamificação de sistemas de EaD para assegurar a competitividade saudável, o estímulo para a realização de atividades e a assiduidade do aluno às aulas, foi o sistema de pontos e recompensas. Baseado na efetiva realização de tarefas e atividades, os pontos acumulados podem ser trocados por prêmios reais e voltados para o maior aproveitamento da experiência acadêmica, como ingressos para museus, privilégios na biblioteca e outros.

Para garantir a facilidade de navegação pela estrutura desenvolvida para o site, foi realizado o teste de usabilidade, que foi fundamental para avaliar a interface do sistema. Com o teste foi possível identificar os pontos que causam mais dúvidas aos usuários e eles puderam opinar sobre como gostariam que ela fosse.

Cabe ressaltar que a metodologia do design thinking não é linear, a volta a conceitos, diagnóstico e implementação podem ocorrer no meio do processo como foi o caso da pesquisa com os jogos.

Neste contexto, este projeto reafirma a metodologia de Design Thinking como uma abordagem focada no ser humano que vê na multidisciplinaridade, colaboração e tangibilização de pensamentos e processos. A inovação guiada pelo design complementa a visão do mercado de que para inovar é preciso focar no desenvolvimento. Ao colocar em questão os padrões atuais apresentados como soluções em EaD para reinventar esta experiência, este projeto indica soluções que geram novos significados e que estimulam os diversos aspectos (cognitivo, emocional e sensorial) envolvidos na experiência humana.

\section{Design Thinking methodology and gamification strategies to reinvent the experience in Distance Learning}

Abstract: How to reinvent the experience of a classroom in the model of Distance Learning? Through the use of the Design Thinking methodology, a model was created to generate alternatives to improve the experience from a case study of Distance Learning recently implanted in an educational institution. Within this context was diagnosed the elements to make a Distance Learning's class more pleasant by focus on learning and using design interface as a means of interaction to present the proposals. The bibliographical research addresses the fundament, evolution and main tools of Distance Education, Instructional Design and Gamification. The choice for gamification was due to high recommendation of the application of this modern strategy in Distance Learning systems, since it proposes to leave the student's experience more pleasant and efficient, maintaining the quality of learning with the proposal to avoid dropping out. The procedures adopted within the Design Thinking methodology cover development of personas, immersion research, mental mapping and prototype analysis and compose a model to apply the methodology to the development of interface to Distance Learning projects. This research is classified as applied as to its nature, qualitative as to its approach, 
exploratory-descriptive in relation to its objectives, and from the point of view of technical procedures it is framed as a case study and reaffirms the design of multidisciplinary activity which introduces new meanings to the human experience.

Keywords: Instructional Design; Design Thinking; Gamification; Interface Design; Experience.

\section{Referências}

AGNER, Luiz. Ergodesign e arquitetura de informação: trabalhando com o usuário. Rio de Janeiro: Quartet, 2006.

ASSOCIAÇÃO BRASILEIRA DOS AGENTES DIGITAIS - ABRADI-SP. Valores Referenciais de Serviços Internos. Disponível em <http://comunicacao.abradi-sp.com.br/guia-vr-abradi-sp> Acesso em 25/06/2017.

ASSOCIAÇÃO DOS DESIGNERS GRÁFICOS DO DISTRITO FEDERAL - ADEGRAF-DF. Tabela Referencial de Valores 2016/2018. Disponível em: <http://www.adegraf.org.br/publicacoes> Acesso em 25/06/2017.

BALEM, Francieli Regina et al. Design Thinking: Conceitos e competências de um processo de estratégias direcionado a inovação. In: Congresso Nacional de Design, 1, 2011 Bento Gonçalves (RS).

BELISÁRIO, Aluízio. O Material Didático na Educação a Distância e a Contribuição de Propostas Interativas. In: SILVA, Marco (org.). Educação online. Edições Loyola: São Paulo. Brasil. 2003. Pg. 137-148.

BRASIL. Diretrizes e bases da educação nacional, decreto No 5.622, de 19 de dezembro de 2005. Ministério da Educação, Brasília, DF. Disponível em: <http://www.planalto.gov.br/ccivil_03/_ato20042006/2005/decreto/d5622.htm >. Acesso em: 10 mai. 2017.

CF7STUDIO. Nós somos o CF7STUDIO. Disponível em: <http://www.cf7studio.com/>. Acesso em 7 jun. 2017.

DANIEL, John; MACKINTOSH, Wayne. "Leading ODL futures in the eternal triangle: the megauniversity response to the greatest moral challenge of our age". In: MOORE, Michael Grahame; ANDERSON, William G. (Es.) Handbook of distance education. Mahwah, NJ: Lawrence Erlbaum, 2003, 817 p, apud MAIA, Carmem; MATTAR, João. ABC da EaD: A educação a distância hoje. 1 ed. São Paulo: Pearson Education, 2007.

DRAW.IO. Disponível em: <https://www.draw.io/>. Acesso em: 17 mai. 2017.

FILATRO, Andrea. Design instrucional contextualizado: educação e tecnologia. São Paulo: Senac, 2004, 65 p apud MAIA, Carmem; MATTAR, João. ABC da EaD: A educação a distância hoje. 1 ed. São Paulo: Pearson Education, 2007.

HELLER, Eva. A psicologia das cores: como as cores afetam a emoção e a razão; [tradução Maria Lúcia Lopes da Silva]; $1^{\text {a }}$ ed. São Paulo: Gustavo Gili, 2013.

IMBODEN, Ethan. Design Thinking: Venture Design. Lynda, 2016. Disponível em: <https://www.lynda.com/Business-Skills-tutorials/Design-Thinking-Venture-Design/495768-

2.html>. Acesso em: 7 jun. 2017.

INAP. Institucional. Disponível em:<http://inap.com.br/portal/institucional/>. Acesso em: 17 mai. 2017.

JOEL, Suzana. Stories for Suzana Joel. Your Story. Disponível em: <https://yourstory.com/author/suzana-joel/> . Acesso em: 7 jun 2017.

KING. Candy Crush Saga. Disponível em: <https://play.google.com/store/apps/details?id=com.king.candycrushsaga\&hl=pt-br>. Acesso em: 20 mai. 2017.

MAIA, Carmem; MATTAR, João. ABC da EaD: A educação a distância hoje. 1 ed. São Paulo: Pearson Education, 2007. 
MARTIN, Roger. The design of business: Why design thinking is the next competitive advantage. Boston: Havard Bussiness Press, 2009 apud BALEM, Francieli Regina et al. Design Thinking: Conceitos e competências de um processo de estratégias direcionado a inovação. In: Congresso Nacional de Design, 1, 2011 Bento Gonçalves (RS).

MENDES, Rosi Mara. Avaliação da interface de desenvolvimento de materiais educacionais digitais no ambiente HyperCAL online. 2009. Dissertação (Mestrado em Design) - Universidade do Rio Grande do Sul, Porto Alegre, 2009.

MUNARI, Bruno. Design e comunicação visual: contribuição para uma metodologia didática. São Paulo:

Martins Fontes, 1997.

MY FONT FREE. Acervo online de fontes gratuitas disponíveis para download. Disponível em: <http://www.myfontfree.com/>. Acesso em: 17 mai. 2017.

OLHAR DIGITAL. Saiba qual é o sistema operacional mais usado no mundo. Disponível em: <https://olhardigital.uol.com.br/noticia/saiba-qual-e-o-sistema-operacional-mais-usado-nomundo/57024>. Acesso em: 17 mai. 2017.

PINHEIRO, Marco Antônio. Estratégias para o Design Instrucional de Cursos pela Internet: um estudo de caso. 2002. Dissertação (Mestrado em Engenharia de Produção) - Universidade Federal de Santa Catarina, Florianópolis, 2002.

PINHEIRO, Tennyson. ABCDesign: Um novo "d"esign. Disponível em:<http://abcdesign.com.br/noticias/um-novo-design/>. Acesso em: 10 mar. 2010 apud BALEM, Francieli Regina et al. Design Thinking: Conceitos e competências de um processo de estratégias direcionado a inovação. In: Congresso Nacional de Design, 1, 2011 Bento Gonçalves (RS).

PLAY DOTS. Two Dots. Disponível <https://play.google.com/store/apps/details?id=com.weplaydots.twodotsandroid\&hl=pt-br>. Acesso em: 20 mai. 2017.

PREECE, Jenny; ROGERS, Yvonne; SHARP, Helen. Design de Interação: Além da interação homemcomputador. Tradução de Viviane Possamia. Porto Alegre: Bookman, 2005 apud MENDES, Rosi Mara. Avaliação da interface de desenvolvimento de materiais educacionais digitais no ambiente HyperCAL online. 2009. Dissertação (Mestrado em Design) - Universidade do Rio Grande do Sul, Porto Alegre, 2009.

PREVEDELLO, Clarissa Felkl. Design de interação e motivação nos projetos de interface para objetos de aprendizagem para EaD. 2011. Dissertação (Mestrado em Design) - Universidade Federal do Rio Grande do sul, Porto Alegre, 2011.

SILVA, Maurício José Vianna; et al. Design thinking: inovação em negócios. 1 ed. Rio de Janeiro: MJV Press, 2012. 162p.

SMITH, Justin. Definindo e Aplicando Personas em Projetos UX. Tradução por Erick Patrick. Publicado em 02/07/2012. Disponível em: <https://webdesign.tutsplus.com/pt/articles/defining-and-applyingpersonas-to-ux-design--webdesign-7561> Acesso em 07/05/2017.

SCHMITT, Bernd. Marketing Experimental. São Paulo: Nobel, 2002.

TAMEIRÃO, Nathália. Gamification: o conceito, as vantagens e aplicação no contexto educacional. Publicado em 04/11/2016. Disponível em: <http://sambatech.com/blog/insights/gamification/> Acesso em: 19/04/2017

TURNER, Amber Leigh. Getting started with user experience design. The Next Web, 2014. Disponível em: <https://thenextweb.com/dd/2014/12/11/elements-user-experience-design/\#>. Acesso em 7 jun. 2017. 